\title{
Effect of High-Frequency Oscillations on Cough Peak Flows Generated by Mechanical In-Exsufflation in Medically Stable Subjects With Amyotrophic Lateral Sclerosis
}

\author{
Jesús Sancho MD, Enric Bures MD, Saray de La Asunción RN, and Emilio Servera MD
}

\begin{abstract}
BACKGROUND: Mechanically assisted coughing with mechanical in-exsufflation (MI-E) is recommended for noninvasive management of respiratory secretions in amyotrophic lateral sclerosis (ALS). To improve the effectiveness of the technique, a new device combining MI-E with highfrequency oscillations (HFO) has been developed. This work aimed to assess the effect of HFO on the cough peak flow generated by MI-E in medically stable subjects with ALS. METHODS: This was a prospective study that included subjects with ALS in a medically stable condition. Cough peak flow generated by MI-E was measured in 4 situations: without HFO, with HFO during insufflation, with HFO during exsufflation, and with HFO in both cycles. The parameters used were: insufflation pressure of $+40 \mathrm{~cm} \mathrm{H}_{2} \mathrm{O}$, exsufflation pressure of $-40 \mathrm{~cm} \mathrm{H}_{2} \mathrm{O}$, insufflation time $2 \mathrm{~s}$, exsufflation time $3 \mathrm{~s}$, amplitude of oscillations $10 \mathrm{~cm} \mathrm{H}_{2} \mathrm{O}$, and frequency of oscillations $15 \mathrm{~Hz}$. RESULTS: Forty-seven subjects with ALS were included: 66\% males, $68.2 \pm 9.2 \mathrm{y}, 40 \%$ with bulbar onset, FVC $=1.7 \pm 1.1 \mathrm{~L}$, percent-of-predicted FVC $=54.4 \pm 26.6 \%$, cough peak flow $=$ $3.8 \pm 2.2 \mathrm{~L} / \mathrm{s}, \mathrm{P}_{\operatorname{Imax}}=-39.4 \pm 26.4 \mathrm{~cm} \mathrm{H} \mathrm{H}_{2} \mathrm{O}$, revised ALS scale $=28.5 \pm 9.3$, Norris bulbar subscore $=26.1 \pm 10.4$. No statistical differences were found in cough peak flow generated by MI-E in the 4 situations (without $\mathrm{HFO}=4.0 \pm 1.2 \mathrm{~L} / \mathrm{s}$, with insufflation $\mathrm{HFO}=3.9 \pm 1.2 \mathrm{~L} / \mathrm{s}$, with exsufflation HFO $=4.1 \pm 1.2 \mathrm{~L} / \mathrm{s}$, with in-exsufflation HFO $=3.9 \pm 1.1 \mathrm{~L} / \mathrm{s})$. CONCLUSIONS: The addition of HFO to mechanically assisted coughing with MI-E does not have an effect on the cough peak flow of medically stable subjects with ALS. Key words: cough-assist, amyotrophic lateral sclerosis, neuromuscular disease, respiratory failure [Respir Care 2016;61(8):1051-1058. (C) 2016 Daedalus Enterprises]
\end{abstract}

\section{Introduction}

Amyotrophic lateral sclerosis (ALS) is a neurodegenerative disease affecting the motor neurons, which leads to

The authors are affiliated with the Respiratory Care Unit, Respiratory Medicine Department, Hospital Clínico Universitario, Valencia, Spain. Drs Sancho and Bures are also affiliated with the Research Group for Respiratory Problems in Neuromuscular Disease, Institute of Health Research INCLIVA, Valencia, Spain. Dr Servera is also affiliated with the Department of Physical Therapy, Universitat de Valencia, Valencia, Spain.

Dr Bures is supported by a grant from the Institute of Health Research INCLIVA, sponsored by Philips-Respironics. The other authors have disclosed no conflicts of interest.

Correspondence: Jesús Sancho MD, Respiratory Care Unit, Respiratory Medicine Department, Hospital Clínico Universitario, Avenida Blasco Ibañez 17, 46010 Valencia, Spain. E-mail: jesus.sancho@uv.es.

DOI: $10.4187 /$ respcare.04552 progressive muscular weakness; the impairment of the respiratory muscles is the principal cause of morbidity and mortality. ${ }^{1}$ In these patients, the main causes of respiratory problems are the progressive loss of ventilatory function, the progressive loss of the capacity to expel secretions by coughing, and the increased risk of aspirations during swallowing. ${ }^{2}$

Patients with ALS lose their ability to clear their airways of respiratory secretions due to the weakness of the inspiratory and expiratory muscles and the dysfunction of the bulbar-innervated muscles, leading to an insufficient or ineffective cough peak flow. ${ }^{2}$ The cough peak flow value is an index of a patient's ability to clear respiratory secretions by coughing. ${ }^{3}$ Values of $<2.7 \mathrm{~L} / \mathrm{s}$ indicate an ineffective cough. ${ }^{4}$

The use of assisted coughing techniques in patients with ALS has been an important advance in their care because it enables respiratory secretions to be controlled without having to resort to invasive methods, such as a fibrobron- 


\section{Mechanically Assisted Coughing IN ALS}

choscopy or even a tracheostomy. ${ }^{5}$ Coughing aids can be both manually assisted and mechanically assisted. ${ }^{6} \mathrm{Me}-$ chanically assisted coughing techniques use a mechanical device that generates positive pressure and provokes the insufflation of the lungs. This is followed almost immediately by an exsufflation with the application of negative pressure. This sudden and rapid change from positive to negative pressure generates air flows during the exsufflation phase, which are capable of clearing the respiratory secretions. ${ }^{7}$ However, despite the fact that various studies have demonstrated the usefulness of mechanically assisted coughing, there are still some important issues that are yet to be resolved: Day-to-day clinical practice has shown that the clearance of thick secretions adhering to the tracheobronchial walls is problematic for mechanically assisted coughing. ${ }^{8}$ To address this problem, a new device (CoughAssist E70, Philips Respironics, Murrysville, Pennsylvania) has recently been designed, which combines mechanical in-exsufflation (MI-E) with high-frequency oscillatory vibrations (HFO). During the cycles of insufflation, exsufflation, or both, this device applies high-frequency oscillatory vibrations, generated by air pulses, to the positive or negative pressures or to both. The frequency settings of these oscillations range from 1 to $20 \mathrm{~Hz}$, and the amplitude settings range from 1 to $10 \mathrm{~cm} \mathrm{H}_{2} \mathrm{O}$. Theoretically, $\mathrm{HFO}$ may facilitate the loosening of these thick secretions to the bronchial wall, enabling them to be cleared. The application of HFO to the airway has been shown to change the viscoelastic properties of the secretions, making them more mobile. ${ }^{9,10}$ Therefore, the addition of HFO to MI-E may be able to facilitate the removal of these tenacious secretions in a noninvasive way during respiratory tract infections in patients with ALS, avoiding the need to resort to invasive methods to expel such secretions.

However, bulbar dysfunction is the main cause of ineffective cough peak flow generated by MI-E in patients with ALS, ${ }^{7}$ and if the main bulbar dysfunction derives from upper motor neuron damage, hyperreflexia episodes in the upper airway may be triggered by mechanical stimuli ${ }^{11}$ such as HFO; this could interfere with the effectiveness of the cough peak flow generated. Therefore, before any evaluation of the clinical effectiveness of the device, the aim of this study was to assess whether the addition of HFO to MI-E could modify the cough peak flow generated by mechanically assisted coughing in medically stable subjects with ALS, either positively or negatively, and whether the oscillations strengthen the effect of ALS patient bulbar dysfunction on the cough peak flow generated.

\section{Methods}

We performed a prospective study from April 2013 to April 2015 that included all subjects diagnosed with ALS according to the Revised El Escorial criteria ${ }^{12}$ who were

\section{QUICK LOOK}

\section{Current knowledge}

Mechanically assisted coughing with in-exsufflation is recommended for noninvasive management of respiratory secretions in amyotrophic lateral sclerosis. However, despite the proven usefulness of mechanically assisted coughing, the clearance of thick secretions adhering to the tracheobronchial walls could be problematic with noninvasive management.

\section{What this paper contributes to our knowledge}

In medically stable subjects with amyotrophic lateral sclerosis, the cough peak flow generated by mechanical in-exsufflation, independent of the severity of bulbar dysfunction, does not change despite the addition of high-frequency oscillations. The presence of air leaks can delay the commencement of the oscillations in the insufflation cycle to a considerable extent.

managed at the Respiratory Care Unit at the Hospital Clínico Universitario (Valencia, Spain). All subjects had to have been in a medically stable condition in the 3 months before inclusion in the study. Informed consent was obtained, and the protocol was approved by the hospital's ethics committee. Exclusion criteria were: refusal to participate in the study, the presence of bronchial disease, a contraindication to the use of MI-E, or the presence of severe frontotemporal dementia associated with ALS that could interfere with the procedures. After inclusion in the study, the subjects underwent a clinical evaluation, mainly oriented toward assessing bulbar impairment, and a functional respiratory evaluation, which included spirometry, the measurement of respiratory muscle strength, and an evaluation of cough capacity.

\section{Clinical Assessment}

Clinical assessment data were collated using the revised ALS scale, ${ }^{13}$ and bulbar dysfunction was evaluated in accordance with the Norris scale bulbar subscore. ${ }^{14}$

\section{Functional Assessment}

Spirometry was performed (MS 2000 spirometer, C. Schatzman, Madrid, Spain) using a mouthpiece and a nose clip. To prevent air leaks from the mouthpiece for those subjects with severe facial weakness, the respiratory function test was performed using an oronasal mask (Matin Vecino, Madrid, Spain). FVC, FEV ${ }_{1}, \mathrm{FEV}_{1} / \mathrm{FVC}$, and supine FVC were recorded in accordance with European 


\section{Mechanically Assisted Coughing IN ALS}

Respiratory Society guidelines and suggested reference values. ${ }^{15}$ The maximum inspiratory pressure and the maximum expiratory pressure were measured in the mouth (Electrometer 78.905, Hewlett-Packard, Andover, Massachusetts) while the check valve was held closed. The maximum inspiratory pressure was recorded close to residual volume, and maximum expiratory pressure was recorded close to total lung capacity. The pressures sustained for $1 \mathrm{~s}$ were measured. Three measurements with $<$ $5 \%$ variability were recorded, and the highest value was used for the data analysis. ${ }^{16}$ Sniff nasal inspiratory pressure was measured in an occluded nostril during a maximal sniff through the contralateral nostril (Micro RPM, MicroMedical Ltd, Rochester, Kent, United Kingdom). Sniff nasal inspiratory pressure was measured during 10 maximal sniffs performed at functional residual capacity, and the highest recorded pressure was used. ${ }^{17}$

Cough peak flow was measured using an oronasal mask (Martin Vecino, Madrid, Spain) connected to a pneumotachograph spirometer (MS 2000) when the subjects performed a maximal cough effort after a deep inspiration. The highest cough peak flow measurement obtained from $\geq 3$ cough maneuvers with $<5 \%$ variability was recorded. ${ }^{5}$ The peak velocity time, or time necessary to reach cough peak flow, was also recorded. Maximum insufflation capacity by air stacking was achieved by the subject taking a deep breath, holding it, and then air-stacking consecutively delivered volumes of air from a manual resuscitator (Revivator, Hersill, Madrid, Spain) through the oronasal mask up to the maximum volume that could be held with a closed glottis. The subject then exhaled the maximally held volume of air into the pneumotachograph for volume measurement. Manually assisted cough peak flow was also measured with the pneumotachograph connected to the mask and the manual resuscitator. ${ }^{5}$

\section{Interventions}

The Cough-Assist E70 (Philips Respironics, Murrysville, Pennsylvania) was used with an oronasal mask (Martin Vecino) and set at an insufflation pressure of $40 \mathrm{~cm} \mathrm{H}_{2} \mathrm{O}$ and an exsufflation pressure of $-40 \mathrm{~cm} \mathrm{H}_{2} \mathrm{O}$, an insufflation/exsufflation ratio of 2:3, and a pause of $1 \mathrm{~s}$ after each cycle. The subjects were asked to try to keep their airways open but to otherwise remain passive and let the CoughAssist device act unimpeded. When HFO were applied, they were set with a frequency of $15 \mathrm{~Hz}$ and an amplitude of $10 \mathrm{~cm} \mathrm{H}_{2} \mathrm{O}$. A pneumotachograph was placed between the mask and the MI-E circuit, and the cough peak flow generated by MI-E, the insufflation volume, and the exsufflation volume were measured. Three measurements with $<5 \%$ variability were recorded, and the highest value was used for the data analysis. Four sessions of MI-E (without oscillation, with oscillations only during insuf- flation, with oscillations only during exsufflation, and with oscillations during both insufflation and exsufflation) were carried out in a random order using a simple randomization method (random number generator by a computer). Washout time sessions of $30 \mathrm{~min}$ were applied to avoid tiredness and hyperventilation of the subject. The acceptability of each MI-E session was measured using a visual analog scale. Subjects were asked to provide a rating in response to the question "How comfortable is this treatment for you?" by making a mark on an uncalibrated $10-\mathrm{cm}$ horizontal line, the left end of which was labeled as "uncomfortable" and the right end of which was labeled "very comfortable." Graphs (flow, pressure, and volume) produced by the device software were analyzed (DirectView. Philips Respironics. Murrysville, Pennsylvania)(Fig. 1 ), and cough peak flow (unassisted and assisted) was considered ineffective when values were $<2.7 \mathrm{~L} / \mathrm{s}$.

\section{Statistical Analysis}

Assuming a risk of 5\% and a power of $90 \%$ to detect differences and basing in our previous results on the SD in cough peak flow generated by MI-E in medically stable subjects ${ }^{7}$ and the mean changes produced in cough peak flow generated by MI-E when set parameters are changed, ${ }^{18}$ a minimum sample size of 26 subjects was calculated as necessary to detect differences.

Data were expressed as mean \pm SD for continuous normally distributed variables and as frequency counts and percentages for binary and categorical variables. Data comparisons were performed using the Student $t$ test and MannWhitney test for normally and non-normally distributed data, respectively; categorical data were compared using the chi-square test. Comparisons for cough peak flow generated by MI-E, insufflation volume, and exsufflation volume between the 4 different sessions of MI-E were performed with an analysis of variance for repeated measurements. Those factors that could influence the effectiveness of mechanically assisted coughing, such as bulbar dysfunction (ALS onset, Norris scale bulbar subscore, revised ALS scale) and the use of mechanically assisted coughing at home, were considered as covariates in the analysis. The level of statistical significance was set at $P<.05$.

\section{Results}

Forty-seven consecutive subjects with ALS in a medically stable condition were enrolled in the study. Time from ALS diagnosis to commencement of the study was $44.8 \pm 50.2$ months. Twenty-one subjects $(44.7 \%)$ used noninvasive ventilation and $22(46.8 \%)$ used mechanically assisted coughing previously at home. Data on demographics, respiratory function, and functional assessment are 

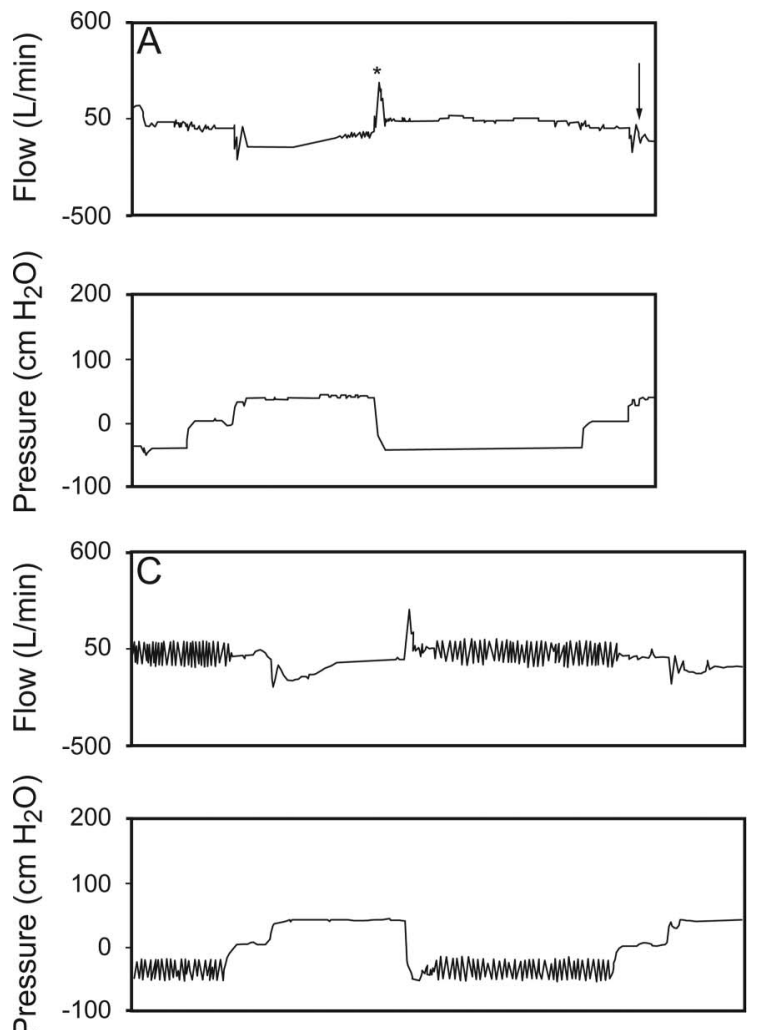
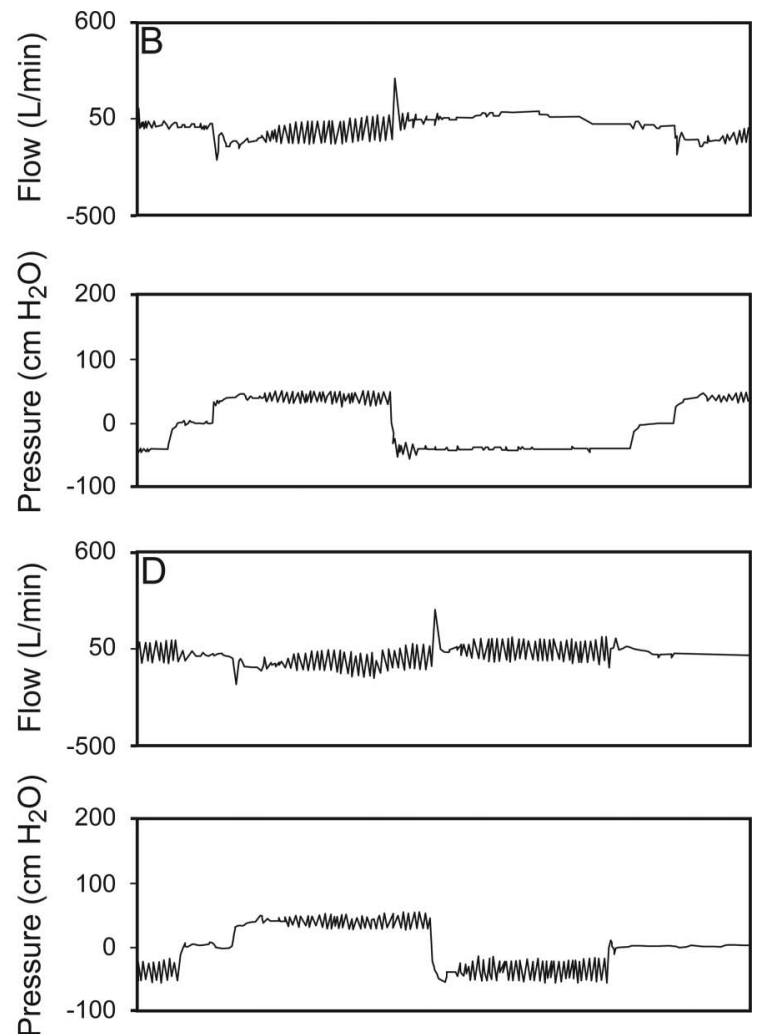

Fig. 1. Flow and pressure waves recorded by the device during the 4 sessions. $A=$ without oscillations; $B=$ oscillations during insufflation; $\mathrm{C}=$ oscillations during exsufflation; $\mathrm{D}=$ oscillations during insufflation and exsufflation. * = cough peak flow generated by mechanical in-exsufflation; arrow indicates elastic recoil.

shown in Table 1. In the spinal onset group, $71.4 \%$ of the subjects presented an effective cough peak flow, and in the bulbar onset group, $31.5 \%$ presented an effective cough peak flow $(P=.004)$.

In the analysis of variance, no statistical differences were found in cough peak flow generated by MI-E, insufflation volume, and exsufflation volume between the 4 sessions tested (no oscillation, with oscillation during insufflation, with oscillation during exsufflation, and with oscillation in both phases) (Table 2). No statistical differences were found in cough peak flow generated by MI-E during the 4 sessions when factors related to the severity of bulbar dysfunction were used as covariates (bulbar onset, $P=.58$; revised ALS scale, $P=.79$; Norris scale bulbar subscore, $P=.99$ ). Using as covariate the presence of an effective cough peak flow, no statistical differences in cough peak flow generated by MI-E were found between the 4 tested sessions $(P=.95)$. No statistical differences were found in the acceptability of each session measured using a visual analog scale (without HFO, $6.6 \pm 2.2 \mathrm{~cm}$; HFO during insufflation, $6.4 \pm 2.2 \mathrm{~cm}$; HFO during exsufflation, $6.1 \pm 2.3 \mathrm{~cm}$; HFO in both phases, $6.1 \pm 2.1 \mathrm{~cm}, P=.35$ ). The acceptability of each session was compared with the severity of bulbar dysfunction and previous use of mechanically assisted coughing at home, and no significant differences were found (bulbar onset, $P=.23$; revised ALS scale, $P=.81$; Norris scale bulbar subscore, $P=.50$; previous mechanically assisted coughing at home, $P=.92$ ).

At the beginning of the exsufflation cycle, a large increase in the flow wave reaching a maximal value was produced; this maximal value represents cough peak flow generated by MI-E. The spikes produced in the flow wave by the oscillations in the exsufflation cycle did not reach the level of cough effectiveness (cough peak flow $>2.7 \mathrm{~L} / \mathrm{s}$ ). At the end of exsufflation and before the pause, a drop in the flow wave was detected. When the oscillations were applied in the insufflation cycle, a delay between the beginning of the insufflation cycle and the oscillations occurred (see Fig. 1). In some cycles in 3 subjects, this delay was so great that the oscillations appeared at the end of the insufflation cycle (Fig. 2). In these cycles, the insufflation volume measured by the device was greater than for the other cycles (subject 1, 3,386 mL vs $2,829 \mathrm{~mL}$; subject 2, 3,556 mL vs 2,292 mL; subject 3, $3,900 \mathrm{~mL}$ vs $2,427 \mathrm{~mL}$ ), the insufflation pressure increased progressively, and the pattern of the flow wave during insufflation changed to a square form, suggesting the presence of air leaks. 
Table 1. Demographic and Pulmonary Function Parameters

\begin{tabular}{|c|c|c|c|c|}
\hline & Total Population $(\mathrm{N}=47)$ & Spinal Onset $(n=28)$ & Bulbar Onset $(n=19)$ & $P$ \\
\hline Male/female sex, $n$ & $31 / 16$ & $23 / 5$ & $8 / 11$ & .008 \\
\hline Age, mean \pm SD y & $68.2 \pm 9.2$ & $67.0 \pm 10.9$ & $70.1 \pm 6.0$ & .28 \\
\hline $\mathrm{BMI}$, mean $\pm \mathrm{SD} \mathrm{kg} / \mathrm{m}^{2}$ & $26.1 \pm 4.4$ & $27.1 \pm 5.2$ & $24.9 \pm 2.8$ & .10 \\
\hline $\mathrm{FVC}$, mean $\pm \mathrm{SD} \mathrm{L}$ & $1.7 \pm 1.1$ & $2.0 \pm 1.0$ & $1.4 \pm 1.1$ & .07 \\
\hline $\mathrm{FVC}$, mean $\pm \mathrm{SD} \%$ predicted & $54.4 \pm 26.6$ & $59.6 \pm 27.7$ & $48.1 \pm 24.5$ & .16 \\
\hline FVCs, mean \pm SD L & $1.4 \pm 1.0$ & $1.6 \pm 1.0$ & $1.1 \pm 1.0$ & .19 \\
\hline $\mathrm{MIC}$, mean $\pm \mathrm{SD}$ L & $2.0 \pm 1.0$ & $2.31 \pm 1.0$ & $1.65 \pm 0.9$ & .039 \\
\hline Cough peak flow, mean \pm SD L/s & $3.8 \pm 2.2$ & $4.5 \pm 2.3$ & $2.8 \pm 1.7$ & .01 \\
\hline Peak value time, mean \pm SD s & $0.2 \pm 0.3$ & $0.1 \pm 0.0$ & $0.3 \pm 0.5$ & .16 \\
\hline $\begin{array}{l}\text { Cough peak flow generated by MI-E, } \\
\text { mean } \pm \text { SD L/s }\end{array}$ & $3.8 \pm 2.2$ & $4.6 \pm 2.2$ & $2.8 \pm 1.8$ & .008 \\
\hline 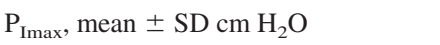 & $-39.4 \pm 26.4$ & $-44.5 \pm 29.8$ & $-32.4 \pm 19.5$ & .14 \\
\hline $\mathrm{SNIP}$, mean $\pm \mathrm{SD} \mathrm{cm} \mathrm{H}_{2} \mathrm{O}$ & $-35.4 \pm 24.7$ & $-42.5 \pm 27.9$ & $-25.5 \pm 14.7$ & .01 \\
\hline $\mathrm{P}_{\text {Emax }}$, mean $\pm \mathrm{SD} \mathrm{cm} \mathrm{H}_{2} \mathrm{O}$ & $68.1 \pm 58.3$ & $82.1 \pm 69.5$ & $48.2 \pm 28.3$ & .064 \\
\hline ALSFRS-R, mean \pm SD & $28.5 \pm 9.3$ & $29.1 \pm 9.6$ & $27.8 \pm 9.2$ & .64 \\
\hline $\mathrm{NBS}$, mean $\pm \mathrm{SD}$ & $26.1 \pm 10.4$ & $31.3 \pm 7.0$ & $18.7 \pm 10.0$ & $<.001$ \\
\hline $\begin{array}{l}\text { BMI }=\text { body mass index } \\
\text { FVCs = supine FVC } \\
\text { MIC = maximal insufflation capacity } \\
\text { MI-E = mechanical in-exsufflation } \\
\text { PIImax }=\text { maximal inspiratory pressure } \\
\text { SNIP = sniff inspiratory pressure } \\
\text { P Emax }=\text { maximal expiratory pressure }_{\text {ALSFRS-r }=\text { revised amyotrophic lateral sclerosis }} \\
\text { NBS = Norris scale bulbar subscore }\end{array}$ & rating score & & & \\
\hline
\end{tabular}

Table 2. Data Generated by Mechanical In-Exsufflation During the 4 Sessions

\begin{tabular}{|c|c|c|c|c|c|}
\hline & Without HFO & HFO During Insufflation & HFO During Exsufflation & HFO During In-Exsufflation & $P$ \\
\hline Cough peak flow ${ }_{\text {MI-E}}$, mean \pm SD L/s & $4.0 \pm 1.2$ & $3.9 \pm 1.2$ & $4.1 \pm 1.2$ & $3.9 \pm 1.1$ & .72 \\
\hline $\mathrm{V}$ insufflation, mean $\pm \mathrm{SD} \mathrm{L}$ & $2.2 \pm 1.2$ & $2.2 \pm 1.2$ & $2.2 \pm 0.9$ & $2.2 \pm 1.2$ & .81 \\
\hline $\mathrm{V}$ exsufflation, mean $\pm \mathrm{SD} \mathrm{L}$ & $2.7 \pm 1.2$ & $2.5 \pm 1.2$ & $2.5 \pm 1.3$ & $2.4 \pm 1.2$ & .68 \\
\hline \multicolumn{6}{|c|}{$\begin{array}{l}\mathrm{HFO}=\text { high-frequency oscillation } \\
\text { Cough peak flow } \\
\mathrm{V} \text { insuff-E }=\text { generated by mechanical in-exsufflation }=\text { volume generated during insufflation } \\
\mathrm{V} \text { exsufflation = volume generated during exsufflation }\end{array}$} \\
\hline
\end{tabular}

\section{Discussion}

The findings of this study show that the addition of HFO to mechanically assisted coughing with MI-E does not have an effect on the cough peak flow of medically stable subjects with ALS, regardless of the severity of bulbar dysfunction. Moreover, we found that the presence of air leaks can interfere with the application of oscillations during the insufflation cycle.

The usefulness and effectiveness of mechanically assisted coughing have been proven in the noninvasive management of respiratory secretions in patients with ALS, $2,5,8$ and it is the recommended treatment for those ALS patients with an ineffective unassisted cough. ${ }^{19}$ However, mechanically assisted coughing is not always an effective technique. The response of the upper airway when there is severe bulbar impairment completely neutralizes the effectiveness of the procedure in clinical practice, ${ }^{7}$ and clinical practice also demonstrates that the increase in secretions and the changes in viscoelastic properties during a respiratory tract infection can also reduce the effectiveness of mechanically assisted coughing, making fibrobronchoscopy necessary for the removal of the secretions. ${ }^{8}$

Although mechanically assisted coughing's effectiveness derives from the quick shift from positive to negative pressure during cycling from insufflation to exsufflation and the large air flows produced, the manufacturer of the Cough-Assist E70 (Philips Respironics) hypothesizes that adding oscillations can contribute to the removal of tenacious secretions, facilitate the process of moving them 

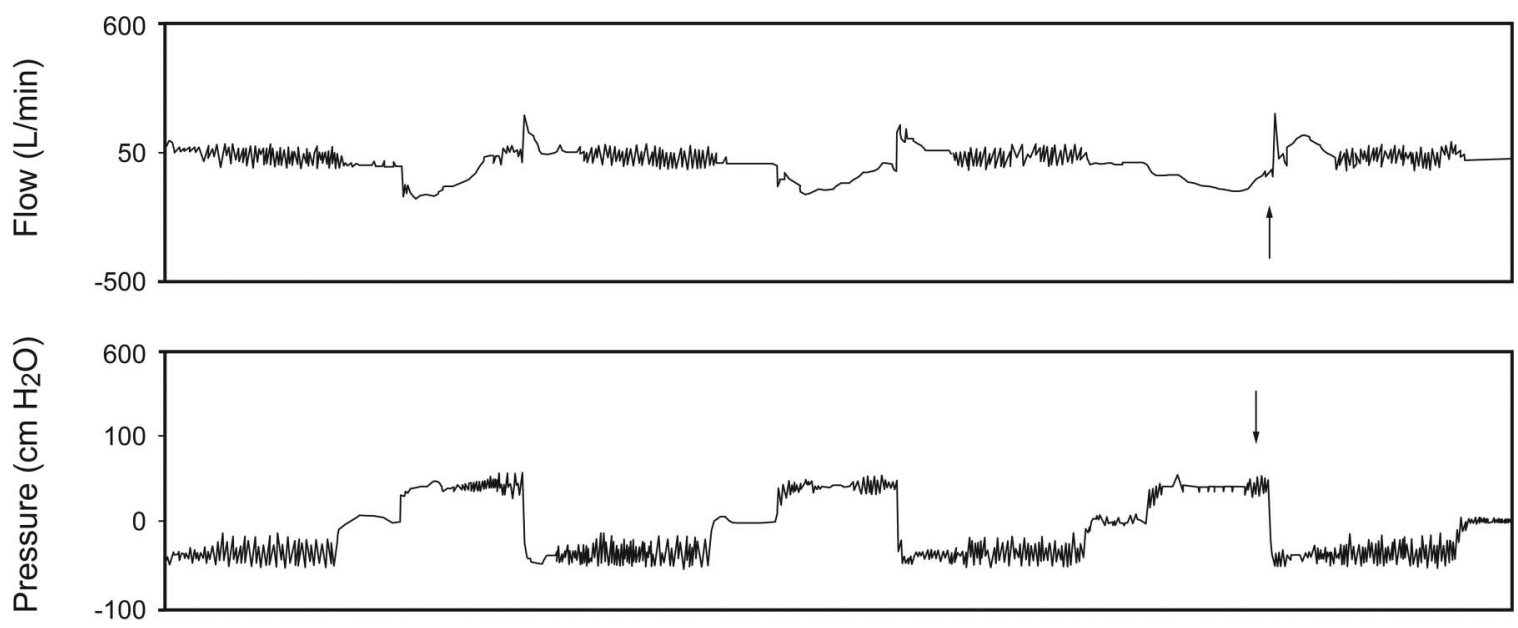

Fig. 2. Flow and pressure waves recorded by the device for one subject. Arrows show a cycle with leaks.

toward the central airways, and improve the amount ultimately expelled. ${ }^{20} \mathrm{~A}$ review of the general literature shows that, within the range of the respiratory pathologies in which hypersecretion of mucus occurs, physical therapies using HFO have been used to mobilize and remove airway secretions. ${ }^{21,22}$ In certain patients, these oscillations may change the viscoelastic properties of the secretions, making it easier to move the mucus up to the proximal airway, where secretion removal is then effected by coughing. In fact, oscillations are not a substitute for an effective cough, but rather their use is meant to enhance the effectiveness of coughing. ${ }^{23}$ This is supported by our current findings because the analysis of the flow waves generated during the exsufflation cycles revealed that the oscillations were unable to reach the necessary magnitude to create an effective cough flow for the removal of the respiratory secretions. Thus, in neuromuscular patients with weak respiratory muscles, other techniques must be used to clear secretions once they have been mobilized centrally by the oscillations. ${ }^{24,25}$ Two previous studies ${ }^{26,27}$ have assessed the effect of high-frequency chest wall oscillations in subjects with ALS. Although the results are not conclusive, both studies show that in those subjects with a decreased cough capacity, respiratory secretions cannot be managed with oscillations alone.

With regard to the use of the device at the bedside, an important finding of the present study is that a delay between the beginning of the insufflation cycle and the onset of the oscillations occurs. When the cycle starts, all of the flow is dedicated to delivering the set pressure because this is considered to be the most important factor, and then, once the set pressure has been reached, oscillations start to be generated. Thus, in the presence of air leaks, the set pressure is reached later, making the delay in the commencement of the oscillations greater. A recent study by Frigerio et $\mathrm{al}^{28}$ found that the presence of air leaks can affect the performance of conventional MI-E. Another feature seen in the flow wave analysis and described previously ${ }^{18}$ is that at the beginning of the pause after the end of exsufflation cycle, a drop in the flow wave occurs due to the elastic recoil of the lung.

Taking into account that bulbar impairment can lead to the passive collapse of the upper airway during the exsufflation cycle in subjects with ALS who are managed with mechanically assisted coughing, ${ }^{7}$ neutralizing its potential therapeutic effect, a question that needs to be addressed is whether the addition of HFO might in fact increase the harmful effect of bulbar impairment on the cough peak flow generated by MI-E. Furthermore, if the bulbar dysfunction derives predominantly from damage to the upper motor neurons, then the bulbar symptoms will be characterized by hyperreflexia episodes in the upper airways. ${ }^{11}$ Thus, from a theoretical point of view, the possibility exists that the HFO could trigger mechanical receptors and induce upper airway reflexes that may impair the performance and the effectiveness of mechanically assisted coughing. Evidence against this hypothesis (and in favor of the device) can be seen in our results because they show that, regardless of the severity of bulbar dysfunction as measured in terms of different parameters, the addition of HFO to mechanically assisted coughing did not produce a change in the cough peak flow generated, and the effectiveness of this technique did not decrease in the ALS subjects studied.

Another finding of the present study is the good level of subject tolerance of the addition of HFO to mechanically assisted coughing. The overall acceptability of the technique was similar with and without oscillations and was not affected by the severity of bulbar dysfunction or the previous use of mechanically assisted coughing at home.

This study has some limitations. The main objective of the present study conducted with medically stable subjects 


\section{Mechanically Assisted Coughing IN ALS}

with ALS unencumbered with secretions was to evaluate the response of the mechanically assisted coughing-generated cough peak flow when HFO were added to MI-E. This is the first protocol from a long-term study in which this technique will be tested in patients with ALS who have an acute respiratory infection. Thus, the results must be taken with caution with regard to acute respiratory episodes, because subjects with ALS suffer an increase in respiratory muscle weakness, a decrease in thoracopulmonary compliance and an increase in airway resistance during a lower respiratory tract infection. ${ }^{8}$ Indeed, these features may lead to the effect of MI-E with HFO being different from the one we have observed here. Another limitation concerns our use of a single value for the frequency and amplitude of the oscillations; we chose these values because they are the ones that are most often employed with the different devices using high-frequency oscillations. ${ }^{29}$ Future studies will be necessary to evaluate the effect of different frequencies and amplitudes of highfrequency oscillations added to MI-E. Finally, the lack of a separate control group represents another limitation; instead of using a group of healthy subjects, our control group consisted of the data from the session of MI-E without HFO.

\section{Conclusions}

In subjects with ALS in a medically stable condition, the cough peak flow generated by MI-E, independent of the severity of bulbar dysfunction, does not change despite the use of HFO during insufflation, during exsufflation, or in both cycles. The presence of air leaks can delay the commencement of the oscillations in the insufflation cycle to a considerable extent. Whether the addition of HFO to mechanically assisted coughing with MI-E will positively impact cough peak flow during acute respiratory infections and improve long term outcomes is still to be determined.

\section{REFERENCES}

1. Lechtzin N, Wiener CM, Clawson L, Chaudhry V, Diette GB. Hospitalization in amyotrophic lateral sclerosis: causes, costs and outcomes. Neurology 2001;56(6):753-757.

2. Bach JR, Bianchi C, Aufiero E. Oximetry and indications for tracheostomy for amyotrophic lateral sclerosis. Chest 2004;126(5):15021507.

3. King M, Brock G, Lundell C. Clearance of mucus by simulated cough. J Appl Physiol 1985;58(6):1776-1782.

4. Bach JR, Saporito LR. Criteria for extubation and tracheostomy tube removal for patients with ventilator failure: a different approach to weaning. Chest 1996;110(6):1566-1571.

5. Sancho J, Servera E, Díaz J, Marín J. Predictors of ineffective cough during a chest infection in patients with stable amyotrophic lateral sclerosis. Am J Respir Crit Care Med 2007;175(12):1266-1271.

6. Bach JR. Update and perspective on noninvasive respiratory muscle aids. Part 2: The expiratory aids. Chest 1994;105(5):1538-1544.
7. Sancho J, Servera E, Díaz J, Marín J. Efficacy of mechanical insufflation-exsufflation in medically stable patients with amyotrophic lateral sclerosis. Chest 2004;125(4):1400-1405.

8. Servera E, Sancho J, Zafra MJ, Catalá A, Vergara P, Marín J. Alternatives to endotracheal intubation for patients with neuromuscular diseases. Am J Phys Med Rehabil 2005;84(11):851-857.

9. Ragavan AJ, Evrensel CA, Krumpe P. Interactions of airflow oscillation, tracheal inclination and mucus elasticity significantly improve simulated cough clearance. Chest 2010;137(2):355-361.

10. King M, Phillips DM, Gross D, Vartian V, Chang HK, Zidulka A. Enhanced tracheal mucus clearance with high frequency chest wall compression. Am Rev Respir Dis 1983;128(3):511-515.

11. Hadjikoutis S, Wiles CM. Respiratory complications related to bulbar dysfunction in motor neuron disease. Acta Neurol Scand 2001; 103(4):207-213.

12. Brooks BR, Miller RG, Swash M, Munsat TL, World Federation of Neurology Research Group on Motor Neuron Diseases. El Escorial revisited: revised criteria for the diagnosis of amyotrophic lateral sclerosis. Amyotroph Lateral Scler Other Motor Neuron Disord 2000; 1(5):293-299.

13. Cedarbaum JM, Stambler N, Malta E, Fuller C, Hilt D, Thurmond B, Nakanishi A. The ALSFRS-R: a revised ALS function rating scale that incorporates assessment of respiratory function. DNF ALS Study Group (Phase III). J Neurol Sci 1999;169(1):13-21.

14. Lacomblez L, Bouche P, Bensimon G, Meininger V. A double-blind, placebo-controlled trial of high doses of gangliosides in amyotrophic lateral sclerosis. Neurology 1989;39(12):1635-1637.

15. Quanjer PH, Tammeling GJ, Cotes JE, Pedersen OF, Peslin R, Yernault JC. Lung volumes and forced ventilatory flows: Report of Working Party "Standardization of Lung Function Test." Eur Respir J 1993;6(Suppl 16):5-40.

16. Black LF, Hyatt RE. Maximal respiratory pressures: normal values and relationship to age and sex. Am Rev Respir Dis 1969;99(5):696702 .

17. Lofaso F, Nicot F, Lejaille M, Falaize L, Louis A, Clement A, et al. Sniff nasal inspiratory pressure: what is the optimal number of sniffs? Eur Respir J 2006;27(5):980-982.

18. Gómez-Merino E, Sancho J, Marín J, Servera E, Blasco ML, Belda FJ, et al. Mechanical insufflation-exsufflation: pressure, volume and flow relationships and the adequacy of the manufacturers' guidelines. Am J Phys Med Rehabil 2002;81(8):579-583.

19. EFNS Task Force on Diagnosis and Management of Amyotrophic Lateral Sclerosis: Andersen PM, Abrahams S, Borasio GD, de Carvalho M, Chio A, Van Damme P, et al. EFNS guidelines on the clinical management of amyotrophic lateral sclerosis (MALS): revised report of an EFNS task force. Eur J Neurol 2012;19(3):360375 .

20. Philips Respironics. Cough Assist E70 User Manual. Murrysville, Pennsylvania: Philips Respironics; 2012.

21. Chatburn RL. High frequency assisted airway clearance. Respir Care 2007;52(9):1224-1235; discussion 1235-1237.

22. Myers TR. Positive expiratory pressure and oscillatory positive expiratory pressure therapies. Respir Care 2007;52(10):1308-1326; discussion 1327.

23. Rubin BK. High frequency external chest wall compression for secretions clearance: shake it, but don't break it. Respir Care 2007; 52(8):982-983.

24. Finder JD, Birnkrant D, Carl J, Farber HJ, Gozal D, Iannaccone ST, et al. Respiratory care of the patient with Duchenne muscular dystrophy: ATS consensus statement. Am J Respir Crit Care Med 2004; 170(4):456-465.

25. Bolton CE, Bevan-Smith EF, Blakey JD, Crowe P, Elkin SL, Garrod $\mathrm{R}$, et al. British Thoracic Society guideline on pulmonary rehabili- 


\section{Mechanically Assisted Coughing in ALS}

tation in adults. Thorax 2013;68:1-30. doi: 10.1136/thoraxjnl-2013203808.

26. Chaisson KM, Walsh S, Simmons Z, Vender RL. A clinical pilot study: high frequency chest wall oscillation airway clearance in patients with amyotrophic lateral sclerosis. Amyotroph Lateral Scler 2006;7(2):107-111.

27. Lange DJ, Lechtzin N, Davey C, David W, Heiman-Patterson T, Gelinas D, et al. High-frequency chest wall oscillation in ALS: an exploratory randomized, controlled trial. Neurology 2006;67(6):991997.

28. Frigerio P, Longhini F, Sommariva M, Stagni EG, Curto F, Redaelli $\mathrm{T}$, et al. Bench comparative assessment of mechanically assisted cough devices. Respir Care 2015;60(7):975-982.

29. Volsko TA, DiFiore J, Chatburn RL. Performance comparison of two oscillating positive expiratory pressure devices: acapella versus flutter. Respir Care 2003;48(2):124-130. 